\title{
Mind the child
}

Citation for published version (APA):

Strik, J. (2021). Mind the child. Maastricht University. https://doi.org/10.26481/spe.20210924js

Document status and date:

Published: 24/09/2021

DOI:

10.26481/spe.20210924js

Document Version:

Publisher's PDF, also known as Version of record

\section{Please check the document version of this publication:}

- A submitted manuscript is the version of the article upon submission and before peer-review. There can be important differences between the submitted version and the official published version of record.

People interested in the research are advised to contact the author for the final version of the publication, or visit the DOI to the publisher's website.

- The final author version and the galley proof are versions of the publication after peer review.

- The final published version features the final layout of the paper including the volume, issue and page numbers.

Link to publication

\footnotetext{
General rights rights.

- You may freely distribute the URL identifying the publication in the public portal. please follow below link for the End User Agreement:

www.umlib.nl/taverne-license

Take down policy

If you believe that this document breaches copyright please contact us at:

repository@maastrichtuniversity.nl

providing details and we will investigate your claim.
}

Copyright and moral rights for the publications made accessible in the public portal are retained by the authors and/or other copyright owners and it is a condition of accessing publications that users recognise and abide by the legal requirements associated with these

- Users may download and print one copy of any publication from the public portal for the purpose of private study or research.

- You may not further distribute the material or use it for any profit-making activity or commercial gain

If the publication is distributed under the terms of Article $25 \mathrm{fa}$ of the Dutch Copyright Act, indicated by the "Taverne" license above, 


\section{Oratie getiteld "Mind the Child "}

behorende bij aanvaarden van de leerstoel “Geestelijke gezondheidszorg bij kinderen met psychiatrische problemen en somatische comorbiditeit" aan de Universiteit van Maastricht

Maastricht, 24-09-21

Jacqueline Julienne Marie Huberthe Strik

Geachte Prorector, collegae hoogleraren, collega's, familie, vrienden en geliefden: vandaag sta ik voor u op een grootse dag. En hoewel ik meestal consciëntieus van aard ben en tracht de dingen zoveel mogelijk op een voorgeschreven wijze te doen, ga ik daar vandaag vanaf zien en ga ik starten met een dankwoord.

Dank aan een ieder die het mogelijk heeft gemaakt mij op deze plaats te krijgen, en in het bijzonder de raden van bestuur van het MUMC+ en de Universiteit Maastricht, en het college van toezicht. Dank voor het vertrouwen dat $u$ in mij gesteld heeft en voor het werk dat ik de afgelopen jaren heb mogen doen. Dank ook aan iedereen die mij, zowel in het werk als privé, zo lang gesteund en gemotiveerd heeft. Mijn senior en junior collegae, het bestuur van de Sint Clemensstichting, maar natuurlijk ook mijn familie, vrienden en dierbaren. En niet in de laatste plaats dank aan mijn collegae die vandaag samen met mij een fantastisch symposium hebben neergezet. Shelly en Suzanne, standbeeld voor jullie! Werken met mensen met dezelfde ambities en interesses....kan men zich iets meer inspirerend voorstellen? Voor u staat dus een dankbaar mens. Maar... het gaat vandaag niet om mij als persoon.... Niet in hoofdzaak wat mij betreft. Wél over wat mij drijft om vandaag voor u te staan en te spreken over het onderwerp van mijn leerstoel. Het gaat vandaag om het kwetsbare kind en meer specifiek een "kwetsbaar" brein in een kwetsbaar lichaam. En wat mijn leerstoel kan daarin bijdragen.

Hiervoor neem ik u eerst mee in de reis naar deze leerstoel toe. "Mind the child" is ontstaan 18 jaar na mijn promotietraject "Mind the Heart". Veel zaken zijn veranderd: niet alleen ben ik 18 jaar ouder 
en heeft mijn aandachtsgebied zich verlegd van de volwassene naar het kind, ook bepalen binnen de geestelijke gezondheidszorg, de GGZ, bij kinderen, de geméentes ondertussen het veld en heeft met name de corona pandemie de wereld op zijn kop gezet, niet in de laatste plaats voor de kwetsbare kinderen en jongeren.

Mijn reis start al eerder, zeker 35 jaar eerder, toen ik met mij toenmalige hond Fifi, een jonge jachthond, een wandeling in het Zuid-Limburgse landschap maakte en nadacht, zoals ik vaak doe als ik met mijn hond loop, over het leven. Dit keer dacht ik na over mijn toekomst en bedacht dat ik beter in plaats van dierenarts of kinderarts-neonatoloog, kinderpsychiater kon worden. Van nabij had ik kwetsbare kinderen gezien en ik wilde iets betekenen voor deze kinderen, voor kinderen met een moeilijke, niet vanzelfsprekende ontwikkeling. Wat maakt dat de een zich goed ontwikkelt en een succes van zijn leven kan maken, terwijl de ander, met ogenschijnlijk dezelfde capaciteiten, mentaal decompenseert en zijn of haar capaciteiten niet kan ontwikkelen? Maar ik wilde ook dokter worden... Kinderpsychiatrie leek me het vak waarin ik beide zaken zou kunnen combineren. Alleen, wie durfde je te zeggen dat je psychiater wilde worden? Het stigma dat op de psychiatrie lag en ligt, was toen niet minder dan nu... "Ga je weer naar die gekken toe..." is een uitspraak ik helaas de dag van vandaag soms nog te horen krijg. Alleen, zoals mijn moeder altijd zei "moeilijk gaat ook". Ik wist dat ik mijn eigen pad, op mijn eigen wijze moest uitstippelen. Ik wilde het stigma helpen verminderen. Om dit goed te kunnen doen moest ik eerst zorgen dat ik op een positie kwam waar ik mee kon praten en beslissen Mijn andere ambities als dierenarts of als kinderarts-neonatoloog, zouden nog wel komen dacht ik, zij het op een andere manier.

Toen ik ongeveer 10 jaar na die wandeling bij mijn toenmalige supervisor Adriaan Honig zat, vroeg hij mij of ik mijn ambities wilde omzetten in een "taart", d.w.z. opleiding tot psychiater, of in een taart met "kers op de taart": een opleiding tot psychiater in combinatie met een promotietraject. Ik had mijn keuze snel gemaakt. Als geborene Zuid-Limburgse was ik een kale taart natuurlijk niet gewend.... 
Daarnaast paste "een kers op de taart" bij mijn ambities: psychiater en dus medisch specialist worden en op een positie komen waar ik mee kon beslissen, mee kon innoveren, en mee kon helpen om een verschil te maken. Het onderwerp van mijn promotieonderzoek, depressie bij patiënten na een hartinfarct, paste bij mijn interesse naar de somatische kant van de psychiatrie, het geheel van lichaam en geest.

Later, als psychiater werkend in het MUMC+, liep ik met mijn toenmalige collega en supervisor in de kinderpsychiatrie Jan Schieveld over de intensive care afdeling van de neonatologie, de NICU, om onrust en agitatie ten gevolge van een delier bij een baby van 29 weken met succes te behandelen. Dat was best spannend, want een delier bij te vroeg geborenen? Wie durfde dat vast te stellen? Of überhaupt te behandelen met medicatie? Ján had eerder onderzoek gedaan naar kinderen met een delier op de kinderintensive care, of de pediatrische intensive care unit, de PICU. Ik vroeg aan Jan: "Moeten we niet de te vroeg geborenen gaan onderzoeken op delier op de NICU?" Want waarom zou een delier zich beperken tot een leeftijd van 2 jaar, of 1 jaar, of nog jonger... Jan keek mij ernstig aan en zei dat dát een onontgonnen gebied was, waar ik waarschijnlijk veel obstakels zou tegenkomen. Mijn antwoord was "moeilijk gaat ook", en de rest is geschiedenis...

Dit toekomstbeeld en deze ambities liggen ten grondslag aan deze leerstoel. In de komende kleine driekwartier zal ik mijn leeropdracht verder toelichten. Kwetsbare kinderen, de relatie van lichaam en geest EN, niet te vergeten, het verminderen van stigma door implementatie van bewustwording en kennis in de klinische praktijk, dát zijn de kernthema's van mijn leerstoel. Als eerste: hoe zit dat nu, lichaam en geest, en hoe zit dat bij kinderen in het bijzonder? Want psychiatrische aandoeningen komen niet zomaar voor. Zeker in kinderen niet. Waar hebben we het eigenlijk over? 
Psychiatrische aandoeningen komen voor bij ongeveer $5 \%$ van de kinderen in de algemene bevolking, lopen op van ongeveer $15 \%$ in kinderen met een somatische aandoening zoals een chronische ziekte tot wel $45 \%$ bij kinderen met epilepsie en breinpathologie. Als een kind dus een somatische ziekte heeft, komen er meer psychiatrische stoornissen voor.

In mijn vak als psychiater is het vaak moeilijk een directe oorzaak van het ontstaan van psychiatrische ziekten aan te wijzen. Meestal ontstaat een mentale ziekte door verschillende factoren: multifactorieel wordt dat genoemd. Een psychiatrische ziekte kan bijv. voorkomen door genetische kwetsbaarheid. Maar ook door een moeizame ontwikkeling bij bijvoorbeeld stress, doorgemaakte trauma's, of breinschade of herseninfectie.

U kunt zich voorstellen dat als kinderen al op jonge leeftijd psychische klachten krijgen, dit een blijvende impact kan hebben op alle levensdomeinen zoals gezin, school, werk, vriendenkring, en dagelijkse activiteiten. Als een kind daarnaast ook nog een lichamelijke ziekte heeft, die tevens een negatieve impact kan hebben op de ontwikkeling en kwaliteit van leven, wordt dat kind dubbel kwetsbaar.

Helaas worden psychiatrische aandoeningen in kinderen vaak niet herkend. Dit, en de dubbele kwetsbaarheid, maken dat het cruciaal is om hier voldoende aandacht voor te hebben.

Helaas gebeurt dat laatste niet altijd, niet bij kinderen met een lichamelijke ziekte, maar ook niet bij kinderen, vooral jonge kinderen, in de GGZ. Binnen de GGZ voor jonge kinderen is er, in tegenstelling tot de GGZ voor kinderen boven de zes jaar, nog steeds sprake van ondersignalering, onderdiagnostiek en onderbehandeling. Landelijk blijkt dat kinderen jonger dan vijf jaar wel tot bijna tien keer minder behandeling krijgen vergeleken met oudere kinderen. Voor de behandeling van kinderen jonger dan twee jaar ligt deze factor nog veel lager. Dit terwijl inmiddels bekend is dat vroegsignalering, preventie (soms al tijdens de zwangerschap) en vroege behandeling van geestelijke 
gezondheidsproblemen, grotere problemen op langere termijn kan voorkomen. Niet voor niets wordt wel gezegd: kinderpsychiatrie is de bakermat van volwassen psychiatrie.

Psychiatrische problemen in kinderen, met name jonge kinderen en kinderen met lichamelijke ziekte, worden dus vaak niet herkend. En hoe zit dat dan andersom, worden lichamelijke problemen in kinderen met psychische problemen ook niet gezien?

Het antwoord is helaas ja...

In de medische wereld wordt er namelijk nog steeds gewerkt met dualisme: het geestelijke en het lichamelijke. Er wordt óf naar het een of naar het ander gekeken.

Binnen mijn eigen vak - de psychiatrie - wordt vaak alleen naar het "geestelijke" aspect gekeken, terwijl binnen de somatiek de focus met name op het lichaam ligt waarbij het functioneren van het brein niet wordt meegenomen. Van het lichaam worden foto's gemaakt en bloedwaarden bepaald, maar een onderzoek naar het functioneren van het brein of het mentale welzijn wordt vaak overgeslagen. Dit dualisme binnen de medische wereld is niet nieuw, het is van alle tijden: Adriaan Honig sprake hier al over in zijn inaugurale rede. Dit dualisme leidt tot suboptimale patiëntenzorg.

De nadelige gevolgen van het dualisme worden in het bijzonder bij kinderen gezien: zij kunnen hun emoties niet goed onder woorden kunnen brengen en uiten emoties vaak lichamelijk: met buikpijn, oorpijn, hoofdpijn, of met afwijkend gedrag zoals onrustig zijn of net "hangerig". Het gevolg kan zijn dat ze bij vertonen van lichamelijke klachten eindeloos lichamelijk onderzocht worden, met het risico op schade door die vele onderzoeken, of dat bij onrust alles weggezet wordt onder "gedragsproblemen" zoals ADHD of autisme.

Hoe deze problematiek, dit thema aan te pakken? Hoe deze dynamiek van psychiatrie en somatiek, in kinderen, te belichten? Mijn idee is: beginnen bij het begin. En dat is: psychiatrie en somatiek samen, heel de mens, een van de leuzen van het MUMC+. 
Deze leerstoel richt zich dus op het geheel van psychiatrie en somatiek; in de dagelijkse praktijk kom ik dat in mijn werk als ziekenhuispsychiater iedere dag tegen.

Laat ik u een voorbeeld geven.

Dit is Jeanne. Jeanne is een niet bestaande patiënte, maar zou het wel kunnen zijn. Jeanne een meisje van 3 jaar, dat werd opgenomen op de PICU met een longontsteking. Zij werd behandeld met antibiotica en beademing, met succes. Gedurende de behandeling werd zij toenemend angstig. De dokters en verpleegkundigen zagen een kleine peuter die helder was, maar slecht aanspreekbaar. Zij staarde rond met een angstige en hulpeloze blik, was afwezig, huilde en was ontroostbaar. Haar spraak was onverstaanbaar en zij wist niet meer hoe ze uit haar tuibeker moest drinken. Haar moeder geeft aan dat "dit haar kind niet is". Ook zíj wordt angstig en vraagt om iets te doen. De dokters kunnen echter geen verklaring geven: de longontsteking ging toch beter?

Bij Jeanne kunt u zien dat haar brein reageert op een ernstige lichamelijke ziekte. Dat komt veel voor, met name als het kind lichamelijk heel ziek oftewel kritisch ziek is. Kritisch ziek zijn betekent dat er levensbedreigend falen bestaat van één of meerdere orgaansystemen van het lichaam, in het bijzonder de belangrijke vitale organen: het hart, de longen of het brein. Deze patiënten worden dan opgenomen op intensive care units. Ten gevolge van het kritisch ziek zijn gaat het brein "mee reageren" en kunnen er psychiatrische symptomen optreden. De "normale" en meest voorkomende reactie op ziek zijn is algemene malaise en aandacht en concentratiestoornissen. We weten allemaal hoe we ons voelen als we erg ziek zijn: dan lukt het bijvoorbeeld niet om zich te concentreren op de krant of het journaal en ligt men het liefste in bed.

Een van de "afwijkende" of pathofysiologische reacties van het brein valt onder de zogenaamde "agitatiesyndromen". Agitatie is een symptoom dat duidt op heel onrustig in je hoofd en in je lichaam zijn, en waarbij patiënten ook verward zijn en kunnen hallucineren. In plaats van agitatie kan de patiënt ook apathie ontwikkelen, dat wil zeggen dat een patiënt té rustig is, te weinig of niet 
beweegt, niet communiceert en zo "door je heen kijkt". Dit type valt vaak niet op, omdat het moeilijk te onderscheiden is van een "gewone rustige" patiënt, zeker in jongere kinderen. Deze twee types, hyperagitatie en apathie, zijn beelden zie je bij een delier ziet. En deze stoornis kunnen zo ernstig worden dat de patiënt eraan overlijdt.

Er was weinig bekend over kinderen met een delier. Net als bij ouderen en volwassenen zorgt delier ervoor dat de kinderen meer risico hebben op slechtere gezondheidsuitkomsten en eerder overlijden, naast de hogere kosten die dit ook met zich meebrengt. Hoe jonger het kind is, hoe groter de kans om een delier te ontwikkelen. Jonge kinderen vormen echter een moeilijke groep om een delier in te onderzoeken, want zij communiceren niet tot slecht, waardoor diverse symptomen van delier niet goed onderzocht. Dit geldt ook voor kinderen met een ontwikkelingsstoornis of minder begaafde kinderen. Dit is niet wenselijk, omdat delier bij deze kinderen op intensive care units ook veel voorkomt, van $20-60 \%$ en de prognose, dus de uitkomst, ook ongunstig is.

Ziekenhuizen moeten van de overheid aangeven hoe hun delier zorg ingeregeld is. Helaas komt dit vaak niet terug in de zorg voor ernstig zieke kinderen. In veel ziekenhuizen is men zich dus niet bewust van het voorkomen van delier bij kinderen; buurlanden ontkennen vaak zelfs dat het voor kan komen. Onderzoek is pas de laatste 20 jaar enigszins op gang gekomen en binnen het onderwijs wordt er vaak niet over gesproken........

Het voorgaande laat het belang zien dat het belangrijk is om de relatie tussen soma en psyche in kwetsbare kinderen proberen te begrijpen om zo uiteindelijk beter op deze problematiek in te kunnen spelen.

Maar hoe zit het nu met soma en psyche buiten het ziekenhuis? Het blijkt dat binnen een ziekenhuis meer aandacht nodig is voor beiden, maar buiten het ziekenhuis wordt bewustwording van dit thema 
mogelijke moeilijker. Eerder hebben we geconstateerd dat de GGZ met name naar de mentale problematiek kijkt en de somatische zorg meer geneigd is zijn vooral naar het lichaam te kijken.

Dan een ander kind, "Antonie". Antonie is een fictieve casus, maar zou zo in de praktijk kunnen voorkomen. Antonie is een 14-jarige jongen, die voor vermoeidheid en buikklachten, al naar diverse kinderartsen was geweest, waarbij nog geen nog geen oorzaak was gevonden. Antonie had echter al vanwege deze klachten veel school verzuimd, terwijl hij op het VWO zat. Om te leren omgaan met zijn klachten werd Antonie naar de GGZ verwezen. Diverse onderzoeken naar hechting en het gezin van Antonie, en behandelingen, poliklinisch en in dagbehandeling volgden. Niets hielp en Antonie zou voor ondertussen ontstane depressieve en suïcidale gedachten worden opgenomen. Uiteindelijk bleek bij een second opinion die de ouders via via bij een medisch psychiatrische afdeling hadden aangevraagd dat er bij Antonie sprake was van een genetisch syndroom, die de bekende, en niet onderzochte andere, lichamelijke klachten kon verklaren. En waardoor Antonie gericht geholpen kon worden, waarbij niet alleen zijn psychische klachten verdwenen, maar ook toekomstige lichamelijke problemen voorkomen konden worden.

De casussen van Jeanne en Antonie staan niet op zich, maar zijn voorbeelden van een groter probleem. Vooral bij kinderen met verschillende aandoeningen, comorbiditeit noemen we dat, en bij jonge kinderen, wordt de juiste problematiek vaak niet herkend.

Hoe komt dat nu, dat dit vroeg signaleren, onderclassificatie en onderbehandeling van psychische problemen bij kinderen onderbelicht blijven? Hier zijn mogelijk een aantal verklaringen voor. De geestelijke gezondheid van jonge kinderen brengt verschillende unieke diagnostische uitdagingen met zich mee vanwege de complexe, onderling samenhangende aard van de ontwikkeling van deze kinderen. Een kind ontwikkelt zich namelijk op verschillende domeinen, lichamelijk, maar ook cognitief, sociaal en emotioneel; en deze domeinen zijn nauw met elkaar verbonden en interactief. Het is daardoor moeilijk, zo mogelijk zelf onmogelijk en onwenselijk om vanuit één bepaalde 
discipline te kijken. Het opsporen van geestelijke gezondheidsproblemen bij kinderen vereist dus een aanpak vanuit diverse perspectieven, een multidisciplinaire aanpak. Hierbij zouden verschillende disciplines nauw met elkaar moeten samenwerken, op zijn minst de kinderpsychiater, kinderpsycholoog en de kinderarts, sociaal pediater of kinderneuroloog. Daarnaast is het moeilijk om ontwikkelingsafwijkingen die bij kinderen worden waargenomen, te onderscheiden van normale ontwikkelingsprocessen aan de ene kant en van klinisch significante psychopathologie, dus stoornis, aan de andere kant. De ontwikkeling van elk kind wordt beïnvloed door temperament en omgevingsfactoren zoals opvoeding, culturele invloeden en sociaaleconomische status. Maar ook van lichamelijke condities. De ontwikkeling in een chronisch ziek kind zal anders zijn dan de ontwikkeling van een lichamelijk gezond kind. Het herkennen van kenmerken van een stoornis in de kindertijd vraagt daarom om aangepaste diagnostische bril maar ook van aangepaste beschrijvingen in de huidige classificatiesystemen. Om die reden zijn naast de huidige versies van deze classificatiesystemen, speciale uitwerkingen voor jonge kinderen ontwikkeld. Echter, in deze uitwerkingen blijft de integratie van somatiek en psyche nog steeds onderbelicht.

Deze diagnostische uitdagingen binnen de GGZ voor jonge kinderen verklaren mogelijk de grote kloof tussen de leeftijdsgroepen wat betreft prevalentie en behandelingspercentages. Dit heeft, nogmaals, een grote impact, aangezien geestelijke gezondheidsproblemen bij kinderen een hoog risico hebben op aanhoudende problemen in de adolescentie en volwassenheid.

Op welke manier kan deze leerstoel voor bovenstaande diagnostische en behandel complexiteit ingezet worden?

Deze leerstoel innoveert een aantal kwalitatieve onderzoeken naar evaluatie van zorg. 
Zo is er binnen het ziekenhuis nieuw observationeel onderzoek naar delier bij kinderen aanstaande en binnen een zeer jonge patiëntengroep, namelijk die van de pasgeborenen op de NICU. Waarom ook bij deze hele jonge kinderen screenen?

Binnen de NICU liggen kinderen die te vroeg geboren worden. Deze kinderen hebben vaak ook somatische complicaties als breinschade, slecht ontwikkelde longen of stofwisselingsstoornissen. Deze kinderen zijn dus vaak oncomfortabel. Gelukkig is er een zorgmodule ontwikkeld om het discomfort van de pasgeborenen op te sporen en te verminderen; deze module heet de Nidcap. Echter, de relatie met delier wordt hierbinnen niet bekeken. Binnen de leeropdracht willen we allereerst onderzoeken of pasgeboren kinderen ook een delier kunnen ontwikkelen en zo ja, hoe hierop te screenen en te behandelen met medicamenteuze en niet-medicamenteuze behandelingen. Uiteindelijk kunnen we de zorg dan op aanpassen door het reeds bestaande zorgprogramma uit te breiden met aandacht voor delier. Daarnaast hopen we ook meer te kunnen begrijpen van het ontstaan en ontwikkelen van een delier binnen een brein.

Hiervoor hebben we samen met de dokters en verpleegkundigen van de NICU een studie gestart waarbij te vroeg geboren kinderen onderzocht op het ontwikkelen van een delier. Wat we in de eerste resultaten zien is dat de mate van ziekte een belangrijke factor is en dat verpleegkundigen essentiële observatoren zijn. Met deze gegevens willen we ook de studie op de PICU herhalen, dus vroegs signalering bij kinderen vanaf 0 jaar. Ook hier is het uiteindelijk doel om zorg voor delier gestandariseerd in het zorgprogramma te krijgen. Internationaal zijn met deze "intensive care" zorgstandaarden, die daar vaak "de ABCDEF" bundel worden genoemd, waarvoor de D voor delier staat, goede resultaten geboekt op welzijn ten tijde van de opname, op langere termijn en ziekenhuiskosten. In deze bundel is ook speciale aandacht voor de F van family care, een thema dat ook hoog in het vaandel staat binnen de visie van het MUMC en dat in ons symposium eerder vandaag reeds ter sprake kwam. 
Naast belang van screenen op delier tijdens opname op de intensive care, is het ook van belang om te weten of kinderen met een delier hier schade op latere leeftijd aan overhouden. Waar wel al aanwijzingen voor zijn is dat kinderen die op een NICU of een PICU hebben gelegen daar op langere termijn psychische stoornissen aan over kunnen houden; stoornissen zoals post-traumatische stress stoornis, ADHD of autisme. Meestal kan de schade niet onder één noemer weggezet worden, maar ondervinden de kinderen algemene ontwikkelingsproblemen, concentratie- en aandachtsproblemen en leerstoornissen: dat wordt ook wel "post intensive care syndrome ", "critical brain injury", of "niet aangeboren hersenletsel" genoemd. Helaas wordt deze breinschade en de gevolgen vaak ook niet herkend of zelfs érkend. Daarom dat binnen het MUMC+ deze kinderen opgevolgd worden, door artsen van de PICU, NICU en onze kinderpsychologen Renske Wassenberg en Sarah Haverbeke. Wat niet bekend is, is of kinderen die op een NICU hebben gelegen of op de PICU, en die ook nog een delier hebben doorgemaakt extra schade ondervinden. Bij ouderen is dat wel bekend; dat delier cognitieve problemen ook op langere termijn kan verergeren. Ook daarom zou het van belang zijn delier in kinderen vroegtijdig op te sporen en te behandelen, eventueel proberen te voorkomen van een delier op zo'n jonge leeftijd.

Daarom gaan er nog twee wetenschappelijke studies starten waarbij de kinderen van de NICU en de PICU opgevolgd worden: één studie naar het effect van vroeggeboorte, met of zonder delier, op eventueel ontstaan van complicaties op latere leeftijd, en een tweede studie naar hetzelfde, maar dan bij kinderen na opname op de PICU .

Uiteindelijk zouden we ons, naast klinisch wetenschappelijk onderzoek, ook meer willen focussen op basaal wetenschappelijk onderzoek en onderzoek naar biologische mechanismen. De multidisciplinaire samenwerking binnen de onderzoeksschool MHeNS, waarin diverse disciplines binnen de medische wereld maar ook basaal wetenschappelijke researchers werken, die tevens ervaring hebben met basaal onderzoek voor de NICU, biedt hiervoor ene uitzonderlijke en uitstekende basis. 
Het voorgaande laat zien hoe binnen het ziekenhuis naar soma en psyche gekeken kan worden. Maar hoe kunnen we eerste herkenning van jonge kinderen met mentale problemen buiten het ziekenhuis bespoedigen? En hoe krijgen we ze meteen op de juiste plek?

Het doel van deze leerstoel is onder andere om de kennis over de tekenen en symptomen van pediatrische geestelijke gezondheid te vergroten door onderzoek te doen naar de GGZ-populatie van jonge kinderen. Een beter begrip en overzicht van de presentatie, classificatie en epidemiologie van psychiatrische stoornissen bij kinderen zal ertoe kunnen leiden dat het makkelijker wordt om screeningsmethodes, klinisch relevante beoordelingsinstrumenten en evidence-based behandeling te vervaardigen en kwalitatief te verbeteren. Dit zou kinderartsen, kinderpsychiaters, kinderpsychologen en andere hulpverleners in staat stellen en ondersteunen om kinderen met psychische problemen en hun families sneller en effectiever te identificeren en te helpen. En het kind sneller op de juiste plek te krijgen OF, en dat is ook een optie, terug naar de huisarts en de "normale" situatie in. Effectieve preventie gericht op kinderen zal waarschijnlijk meer persoonlijke sociale en economische voordelen opleveren.

Binnen een van onze pilot studies die we binnen en in samenwerking met de Mutsaersstichting mochten doen is gekeken naar de symptomen van de verwezen GGZ-populatie, dat waren kinderen van 0-6 jaar. Ook werd er gekeken naar hun verwijzing, eventuele eerdere interventies met betrekking tot deze symptomen en de uiteindelijke diagnose. De eerste resultaten lieten zien dat bij een gemiddelde leeftijd van nog geen 3 jaar de kinderen al 2 of meer andere hulpverleners hadden gezien voordat ze bij de Mutsaersstichting kwamen. En dat de meerderheid van de kinderen complexe klachten had waaronder ook somatische klachten. Maar dat met name die somatische klachten niet geïnventariseerd werden waarbij vooral werd gekeken naar de hechting en 
systeemdynamiek. Opnieuw een teken dat een geïntegreerde blik naar het kwetsbare kind nog niet gestandariseerd is. Dus hoe dit aan te pakken?

Gezien het belang van integratie van psyche en soma bij kinderen werkt deze leerstoel toe en naar een aantal implementatie's en innovaties in de praktijk door middel van integratie van kliniek, opleiding en onderwijs, en onderzoek.

Binnen de opleiding psychiatrie in het MUMC+ zijn dan ook deze drie sectoren uitgewerkt om deze verbinding te integreren.

Als eerste uitbreiding van opleidingsplekken kinderpsychiatrie. Met het nieuwe landelijke opleidingsplan waarin kinderpsychiatrie niet alleen als keuzevak kan gekozen worden, maar nu ook een verplicht onderdeel is van de opleiding, is de noodzaak geboren om meerdere stageplekken te voorzien. De opleiding Psychiatrie binnen het MUMC+, die ik samen met de medische staf en met name met de onuitputtelijke bijdrage van mijn collega opleider Marijntje Tijssen in de laatste vijf jaar heb mogen uitbreiden van één naar vier instroom plaatsen per jaar is hierin een van de belangrijke schakels. Onder de vlag van en in samenwerking met de opleiding zijn reeds nieuwe stageplekken van kinderpsychiatrie opgezet. Nieuwe erkenningen zijn samen met collega opleiders aangevraagd met Youz, een ambulante instelling voor kinder GGZ en met de Mutsaers Stichting, een instelling voor kinder GGZ en jeugdzorg. Langer bestaande samenwerkingen van 45 jaar met het Zuyderland ziekenhuis in Heerlen/Sittard, MET GGZ Roermond/Echt en Mondriaan Maastricht/Heerlen laat zien dat samenwerking met de betreffende opleiders en binnen instellingen tot een steviger regionaal opleiding circuit kan leiden. Daarnaast is wetenschappelijk onderzoek binnen de opleiding Psychiatrie meer geïntegreerd. Binnen het MUMC+ hebben de arts-assistenten structurele tijd voor onderzoek of onderwijstaken, afgestemd op hun persoonlijke behoeften. Een voorbeeld heeft u gezien tijdens het symposium eerder vandaag bij de voordracht van een van de arts-assistenten Husam Salamah die vertelde over de relatie tussen soma en psyche bij het kind. 
Ook binnen het onderwijs van studenten geneeskunde van onze Universiteit is het thema kinderziekenhuispsychiatrie geïntegreerd. Dit komt voor in de seminars binnen de co-schappen maar ook als mogelijkheid voor de semi-artsen om zowel klinische als wetenschappelijke stages te doen. Zoals Kim Tijssen die heeft meegewerkt over ons onderzoek op de NICU. Ook master studenten van de Faculteit Psychologie en hebben hun wetenschappelijke stage binnen onze researchlijn afgesloten. Zie hiervoor het voorbeeld van Nina Bongers over somatiek binnen de kinder GGZ. Diverse Bachelor gezondheid wetenschap studenten hebben in de afgelopen jaren hun thesis binnen onze onderzoekslijn verricht. Op deze manier komen studenten niet alleen in aanraking met het thema maar ook kunnen zo toekomstige collega worden gescout. Een ander voordeel hierbij is toegenomen samenwerking, niet alleen binnen de diverse onderdelen van de faculteit FHML maar ook tussen de diverse faculteiten, zoals FPN. Hierin wordt de mate van multi disciplinariteit verstevigd.

Niet alleen toekomstige artsen, psychiaters en psychologen worden zo opgeleid, ook is er een opleidingsplaats voor verpleegkundig specialisten gespecialiseerd in de kinderpsychiatrie gerealiseerd. Daarnaast, gezien integratie op diverse nivo's van belang is, zijn in combinatie met de NICU en PICU , mogelijkheden gecreëerd voor verpleegkundigen om expertise op te doen en/of te academiseren. Dit past binnen het strategisch plan van MUMC om het zeer belangrijke vak van verpleegkunde te specialiseren, innoveren en academiseren. Zo werken verpleegkundigen van de NICU samen met het klinisch onderzoek; en is er een masterverpleegkundige die opgeleid wordt binnen de research thema's. Eenzelfde project hopen we te starten binnen de PICU. Binnen de researchlijn is daarnaast een verpleegkundig specialist in opleiding die als expertise liasionpsychiatrie, ook binnen kinderpsychiatrie heeft. Tenslotte hebben ook fellows binnen de diverse specialismen als kinderintensivisten en neonatologen de mogelijkheid om onderzoek te doen binnen hun eigen werkveld met een eventuele promotie tot gevolg. Door deze manier van interdisciplinair 
samenwerking in wetenschap en onderwijs wordt de samenwerking op de werkvloer en dus in de patiëntenzorg geïntensiveerd.

Zoals genoemd is multidisciplinaire samenwerking binnen de ziekenhuispsychiatrie van het grootste belang. Door op deze manier klinisch evaluatief onderzoek te verrichten wordt niet alleen kennis vergroot maar ook een stevigere samenwerking beoogd. Deze samenwerking wordt niet alleen versterkt binnen het MUMC+, maar ook met de regionale samenwerkings partners. Door junior collega binnen de opleiding in elkaars instelling te laten werken, door onderwijs met elkaar uit te wisselen en door zichtbaar te zijn binnen elkaars kliniek, wordt ketenzorg geoptimaliseerd. Dit betekent dat verwijzing van en naar elkaar makkelijker wordt en ook inhoudelijk door kortere lijnen beter afgestemd kan worden. Daarnaast biedt dit de mogelijkheid tot professionalisering en kwaliteit verhoging van ieders klinische praktijk. Beoogd wordt door snellere een betere triage het kwetsbare kind meteen op de juiste plek te krijgen.

Om impact te verhogen en multidisciplinaire samenwerking verder te verstevigen, is verspreiding hiervan van lokaal binnen het ziekenhuis en omliggende samenwerking's partners, naar regionale samenwerkings partners en landelijke samenwerkings partners van belang. In Nederland zijn er weinig universitaire centra die kinderpsychiatrie op de kaart hebben staan en nog minder die de relatie tussen kinderpsychiatrie en somatiek voor ogen hebben. Door het voorzitterschap van de multidisciplinaire richtlijn voor het kinderdelirium twee keer op rij verzorgd te hebben, wordt zichtbaarheid en herkenbaarheid van de thema vergroot en multidisciplinaire samenwerking versterkt. Door internationaal zichtbaarheid binnen de board van de European association for delirium en internationale webinars, wordt bekendheid van het thema vergroot, alsmede mogelijkheden tot samenwerking binnen internationaal wetenschappelijk onderzoek. Voorbeeld is samenwerking met Engeland, lerland en Australië om zorg voor delier van kinderen op de intensive care units te vergroten door onder Delphi projecten gestalte te geven; of met de Verenigde Staten 
wetenswaardigheden rondom screenen op pediatrisch delier uit te wisselen. Materialen voor onderwijs worden over en weer uitgewisseld. Diverse internationale papers zijn reeds gepubliceerd en meerdere hoofdstukken over het kinderdelier en kinderen met brein infecties nationaal en internationaal zijn uitgekomen.

Maar terug naar de lokale zorg. Zoals gezegd hebben de verschuiving van de gelden voor kinder en jeugd GGZ naar de gemeenten hun tol geëist. Daarnaast heeft de corona pandemie van afgelopen twee jaar niet alleen de patiëntenzorg stilgelegd, maar ook mentale problemen verhoogd binnen kwetsbare kinderen zoals kinderen met gedragsproblemen, geestelijke beperkingen en adolescenten. Subsidies van de overheid zullen geen effect hebben als instellingen hun eigen eilandje blijven bedienen. Ook hier is samenwerking en elkaar aanvullen in plaats van beconcurreren van belang. Vandaar noodzaak voor ketenzorg door samenwerking van universitaire en perifere instelli ngen op het gebied van kliniek, onderwijs en opleiding, en wetenschap. Het verbeteren van de algemene bekendheid van wat geestelijke gezondheidsproblemen in het kinderbrein omhelzen en dat de somatische ontwikkeling hier niet los gezien van kan worden zal niet alleen de zorg en de multidisciplinaire samenwerking verbeteren, maar hopelijk stigmatisering verminderen en het proces van op de juiste plek krijgen van het juiste kind versnellen. Ook minder conventionele behandelingen binnen de kinderpsychiatrie, zoals dierentherapie, oftewel animal assisted therapy, zoals die we al kennen binnen revalidatie trajecten en zorg voor slechtzienden, zouden meer aandacht verdienen. Tegen het einde van mijn rede zou ik nog iets toe willen voegen aan de persoonlijke reis die ik heb afgelegd naar deze dag. Deze dag draait om waarheen deze leerstoel kan leiden. Voor mij is die weg begonnen met interesse in de levenswegen van de mens. Waarom eindigt die voor de een zoveel gecompliceerder en onfortuinlijker dan voor de ander, ook als geslacht, leeftijd en verwantschap grotendeels identiek zijn? En psychosociale omstandigheden, opleiding en regio van herkomst grotendeels aan elkaar gelijk zijn? Hoe kunnen levenspaden zo verschillen? Dat ouders van het ene 
kind uitgenodigd worden voor een feestelijke promotie; de andere voor een uitvaart vanwege een zelfgekozen levenseinde....Mijn vragen blijven vooralsnog onbeantwoord. Maar wat ik wel weet, en al wist tijdens wandelen met mijn hond, nu 35 jaar geleden, waarin ik nadacht over waarheen mijn pad moest leiden dat ik onfortuinlijke kinderen, kinderen met een niet vanzelfsprekende ontwikkeling, wilde helpen. Het liefst in combinatie met mijn liefde voor dieren. De uitkomst van mijn pad zal u duidelijk zijn.

Voor u staat een dankbaar mens. Dankbaar dat ik dagelijks op het enthousiasme en inzet van mijn collegae binnen en buiten het ziekenhuis en de Universiteit, kan rekenen; dankbaar voor de onuitputtelijke en onvoorwaardelijke steun van mijn familie en schoonfamilie, ouders, broer en mijn gezin. Dat het leven mij de mogelijkheden, de talenten, de mentale veerkracht en de liefde heeft gegeven om mijn levenspad tot aan dit punt te hebben kunnen bewandelen. Ik hoop in mijn toekomstige pad verder deze zegeningen in te kunnen zetten voor de vroeg-kwetsbaren onder ons.

Ik heb gezegd. 